Monica Brunschwiler MD,

Elisabeth Van Gessel MD,

Alain Forster MD,

Alison Bruce $\mathrm{MD}$,

Zdravko Gamulin MD

\title{
Comparison of clonidine, morphine or placebo mixed with bupivacaine during continuous spinal anaesthesia
}

Purpose: To compare intraoperative anaesthetic and haemodynamic effects of clonidine-bupivacaine, morphine-bupivacaine and placebo-bupivacaine combinations during continuous spinal anaesthesia.

Methods: Thirty six geriatric patients, undergoing knee replacement using continuous spinal anaesthesia were randomly assigned to: Placebo $(n=12)$, clonidine $(n=12)$ and morphine $(n=12)$, where $1 \mathrm{ml}$ saline, $0.15 \mathrm{mg}$ clonidine or $0.15 \mathrm{mg}$ morphine were mixed with $10 \mathrm{mg}$ bupivacaine $0.5 \%$. Anaesthetic variables studied were maximal sensory level and degree of motor block, duration of surgical analgesia and duration of anaesthesia . Changes in systolic arterial pressure and vasopressor requirements were evaluated.

Results: Maximal sensory level and degree of motor block were comparable among the groups. Before surgery two patients in the placebo group, three in the clonidine and one in the morphine group received one additional $\mathrm{ml}$ bupivacaine $0.5 \%$ because of inadequate anaesthesia and were not considered for determination of duration of surgical analgesia. In the remainder, $1 / 9$ in the clonidine group, $8 / 10$ in placebo and $8 / 11$ in morphine $(P<0.05)$ received reinjection of bupivacaine for surgical pain. These injections were given about $21 / 2 \mathrm{hr}$ after the initial intrathecal injection, the duration of anaesthesia being about four hours. During the first $30 \mathrm{~min}$ after the initial injection the decrease in systolic pressure was greater in the clonidine and morphine than in the placebo group $(P<0.05)$. Thereafter, vasopressor requirements were higher only in the clonidine group $(P<0.05)$.

Conclusion: In elderly patients $0.15 \mathrm{mg}$ clonidine but not $0.15 \mathrm{mg}$ morphine prolonged surgical analgesia when added to $10 \mathrm{mg}$ plain bupivacaine.

Objectif : Le but de cette étude était de comparer les effets analgésiques et hémodynamiques per-opératoires de combinaisons clonidine-bupivacaïne, morphine-bupivacaine et placebo-bupivacaine pendant une anesthésie rachidienne continue.

Méthode : Trente six patients âgés, subissant la mise en place d'une prothèse totale de genou sous anesthésie rachidienne continue ont été assignés de façon randomisée dans l'un des groupes suivants : Placebo $(n=12)$, donidine $(n=$ 12) ou morphine $(n=12)$. Un ml de $\mathrm{NaCl} 0,9 \%, 0,15 \mathrm{mg}(\mathrm{I} \mathrm{ml})$ de clonidine ou $0,15 \mathrm{mg}(1 \mathrm{ml})$ de morphine étaient mélangés à $10 \mathrm{mg}(2 \mathrm{ml})$ de bupivacaine $0,5 \%$. Les variables étudiées étaient le niveau sensitif maximal atteint, le degré du bloc moteur, la durée de l'analgésie chirurgicale (le temps entre l'injection initiale et l'appantion d'une douleur pendant l'acte chirurgical) et la durée de l'anesthésie (le temps entre l'injection initiale et la fin de la chirurgie). Les changement de la pression artérielle systolique et les besoins en vasopresseurs étaient évalués.

Résultats : Le niveau sensitif maximal et le degré de bloc moteur étaient comparables entre les groupes. Avant la chirurgie deux patients du groupe placebo, trois du groupe clonidine et un du groupe morphine ont dû recevoir I $\mathrm{ml}$ supplémentaire de bupivacaine $0.5 \%$ en raison d'une anesthesie insuffisante; ils n'ont pas été pris en compte pour la détermination de la durée de l'analgésie chirurgicale. Parmi les patients restants, seul $1 / 9$ dans le groupe clonidine par rapport à $8 / 10$ dans le groupe placebo et $8 / 1$ I dans le groupe morphine $(P<0,05)$ ont reçu une réinjection de bupivacainne pour une douleur chirurgicale. Ces injections ont dû être administrées environ $2,5 \mathrm{~h}$ après l'injection intrathécale initiale, la durée de l'anesthésie étant d'environ 4 heures. Pendant les 30 premières minutes après l'injection initiale, la diminution de la pression artérielle systolique était plus grande dans les groupes clonidine et morphine comparés au groupe placebo $(P<0,05)$. Par la suite, les besoins en vasopresseurs étaient plus élevés uniquement dans le groupe clonidine $(P<0,05)$. Conclusion : Chez des patients âgés, $0,15 \mathrm{mg}$ de clonidine, contrairement à $0,15 \mathrm{mg}$ de morphine, prolongent l'analgésie chinurgicale quand ils sont associés à $10 \mathrm{mg}$ de bupivacaïne.

From the Department of Anacsthesiology, University Hospital of Geneva, 1211 Genève 14, Switzerland.

Address correspondence to: Dr M Brunschwiler, Département d'Anesthésiologie, Hôpital Cantonal Universitaire, 1211 Genève 14, Switzerland. Phonc: 022-372-33-11.

Accepted for publication May 15, 1998. 
A LTHOUGH clonidine ${ }^{1-4}$ and morphine $e^{4-8}$ are frequently used as adjuvants during spinal anaesthesia, to enhance postoperative analgesia, their comparative intraoperative anaesthetic and haemodynamic effects are poorly documented. The results of a study comparing the combination of clonidine, of morphine or a placebo with bupivacaine suggest that clonidine prolongs the duration of spinal anaesthesia, whereas morphine produces superior postoperative analgesia. ${ }^{4}$ However, these results were obtained during single injection spinal anaesthesia, a technique which requires a large dose of local anaesthetic and does not allow precise evaluation of the possible intraoperative effects of the combination of these agents.

The aim of the study was to compare, during the intraoperative period, the anaesthetic and haemodynamic effects of the addition of $0.15 \mathrm{mg}$ clonidine, 0.15 $\mathrm{mg}$ morphine or placebo to $10 \mathrm{mg}$ bupivacaine using continuous spinal anaesthesia for total knee replacement surgery. Our hypothesis was that the use of smaller doses of local anaesthetic during continuous spinal anaesthesia should allow a more precise evaluation of the different effects of the adjuvants and, in particular, exact determination of the duration of surgical analgesia by measuring the time elapsed from the intrathecal injection and the appearance of pain at the operative site during surgery. ${ }^{9,10}$ The term surgical analgesia, as defined, is not equivalent to sensory block. As demonstrated previously, ${ }^{11}$ the level of sensory block, determined by the pin-prick test, does not always indicate effective surgical analgesia.

\section{Method}

After approval from the Ethics Committee of our institution and informed consent, 36 patients, older than $75 \mathrm{yr}$, ASA II or more, and who were scheduled for elective total knee replacement under continuous spinal anaesthesia, participated in the study. Meperidine $0.5 \mathrm{mg} \cdot \mathrm{kg}^{-1}$ mixed with $0.25 \mathrm{mg} \cdot \mathrm{kg}^{-1}$ promethazine was administered to all patients one hour before the scheduled surgery. In the operating room standard monitoring, including non-invasive blood pressure, continuous ECG and pulse oxymeter was instituted. A peripheral intravenous line and urinary catheter were inserted in each patient. Further invasive monitoring was used if required by the patients' clinical condition. Preanaesthetic fluid loading consisted in the administration of $10 \mathrm{mg} \cdot \mathrm{kg}^{-1}$ of Ringers's-Lactate solution before the intrathecal administration of the local anaesthetic. Thereafter, administration of crystalloids and/or blood was adjusted according to haemodynamic variables and estimated blood loss.
Continuous spinal anaesthesia was performed with the patient in the lateral decubitus position, at the $\mathrm{L}_{2-3}$ or $\mathrm{L}_{3.4}$ interspace, using the median approach, with an 18 gauge Tuohy needle. After observing cerebrospinal fluid reflux, a 20 gauge catheter was inserted in a cephalad direction and left $3-4 \mathrm{~cm}$ in the subarachnoid space. The patient was then placed supine until the end of the operation. Oxygen via mask was administered during surgery and in the recovery room.

The patients were randomized into three groups and received one of the three following solutions in a double blind fashion:

- Placebo: $2 \mathrm{ml}(10 \mathrm{mg})$ plain bupivacaine $0.5 \%$ and $1 \mathrm{ml} \mathrm{NaCl} \mathrm{0.9 \%} \mathrm{(total} \mathrm{=} 3 \mathrm{ml}$ );

- Morphine: $2 \mathrm{ml}$ plain bupivacaine $0.5 \%$ and 0.15 $\mathrm{mg}$ morphine in $1 \mathrm{ml}$ (total $=\mathbf{3} \mathrm{ml}$ );

- Clonidine: $2 \mathrm{ml}$ plain bupivacaine $0.5 \%$ and 0.15 $\mathrm{mg}$ clonidine in $1 \mathrm{ml}$ (total $=3 \mathrm{ml}$ ).

The speed of injection was $1 \mathrm{ml}$ per 10 seconds. The variables measured included:

- Level of sensory block assessed by pinprick using a 24 gauge needle every five minute during the first $30 \mathrm{~min}$, then every $15 \mathrm{~min}$ until the first reinjection or the end of the operation;

- Degree of motor block evaluated every five minute during the first $30 \mathrm{~min}$ according to the modified Bromage scale ( $0=$ no motor block; $1=$ unable to move hip, able to move knee, ankle and toes; $\mathbf{2}=$ unable to move hip and knee, able to move ankle and toes, $\mathbf{3}=$ unable to move hip, knee and ankle, able to move toes; $4=$ complete motor block);

-Duration of surgical analgesia, the time from the initial intrathecal injection until the first reinjection, required by the appearance of pain at the operative site;

-Duration of anaesthesia, - time from the initial intrathecal injection and the end of surgery.

If, 30 min after the initial intrathecal injection, the sensory level was $<\mathrm{L}_{1}$ and/or the motor block $<$ grade 2 on the Bromage scale, the patient received $1 \mathrm{ml}$ plain bupivacaine $0.5 \%$ and was excluded from the calculation of the duration of surgical analgesia. The same dose of bupivacaine was administered when pain appeared at the operative side during surgery.

The haemodynamic variables, which included arterial pressures and heart rate, were recorded every 2.5 min during the first $30 \mathrm{~min}$ after the intrathecal injection, and then every five minute until the end of the operation. Vasopressors (ephedrine) and anticholinergics (atropine) were administered if the systolic arterial blood pressure decreased by $>30 \%$ of baseline value and if a clinically important bradycardia developed. 
The sedation score $(1=$ awake and alert, $2=$ sedated, responds to verbal stimulus, $3=$ sedated, responds to mild physical stimulus, $4=$ sedated, responds to moderate or strong physical stimulus, $5=$ not arousable) and the respiratory rate were determined every $15 \mathrm{~min}$.

In the postoperative period, analgesia consisted in the administration, as required, of $75 \mathrm{mg}$ diclofenac $i m$ (maximum $\times 3 / 24 \mathrm{hr}$ ) and/or of $0.1 \mathrm{mg} \cdot \mathrm{kg}^{-1}$ morphine sc (maximum $\times 6 / 24 \mathrm{hr}$ ).

The following variables were recorded:

- time from the end of the operation to the first dose of analgesia;

- total number of analgesic interventions over the first $24 \mathrm{hr}$;

- secondary effects, such as nausea, vomiting and pruritus.

All results are expressed as mean $\pm S D$, or as median (range) for ordinal data. Analysis of variance, the Kruskall-Wallis test, and the $X^{2}$ or Fisher's exact test were used as required.

\section{Results}

There were no demographic differences among groups (Table I). No differences were found among the three groups in the evolution of sensory level over the first 30 min after the initial intrathecal injection (Figure 1). Similarly, the maximum median sensory level and the time taken to achieve this level were comparable (Table II). There was also no difference in the maximal degree of motor block during the first 30 min after injection, nor in the time elapsed to reach it (Table II).

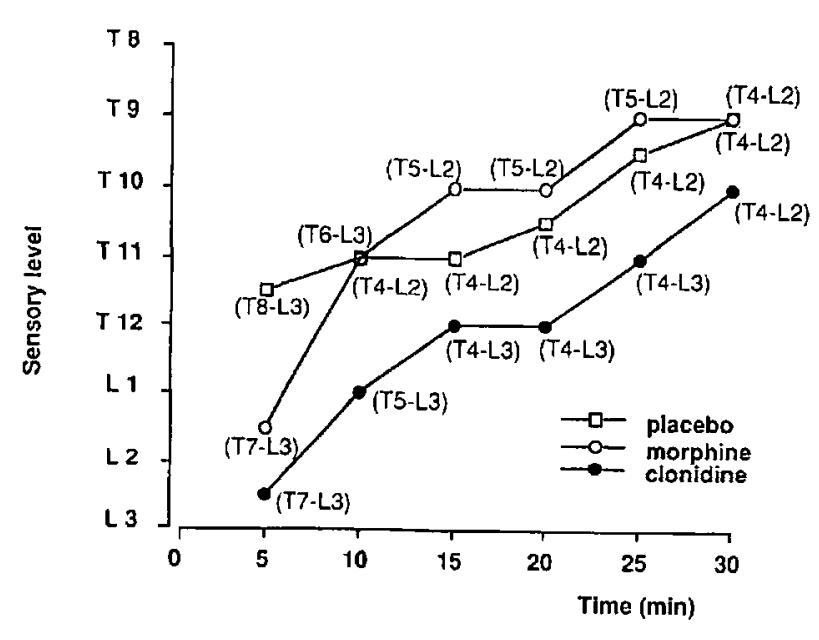

FIGURE 1 Evolution of sensory block during the first $30 \mathrm{~min}$ after initial injection.

Median (range), $\mathrm{n}=12$ in each group.
Thirty minutes after the initial intrathecal injection, two patients in the placebo group, one in the morphine and three in the clonidine group presented a sensory level $<\mathrm{L}_{1}$ and/or a motor block $<2: 1 \mathrm{ml}$ plain bupivacaine $0.5 \%$ was thus administered before starting surgery. These patients were not included in the calculation of the duration of surgical analgesia.

Intraoperatively, in the remaining patients, the appearance of pain at the surgical site required reinjection of $1 \mathrm{ml}$ bupivacaine $0.5 \%$ in $8 / 10$ and $8 / 11$ patients in the placebo and the morphine groups respectively, whereas only $1 / 9$ patients in the clonidine group required reinjection $(P<0.05)$. The median level of sensory block observed just before reinjection was: $T_{11} .5\left(T_{5}-L_{2}\right)$ for the placebo group, $T_{12}\left(T_{5}-L_{2}\right)$ for

TABLE I Patients characteristics (mean $\pm S D, n=12$ in each group)

\begin{tabular}{llll}
\hline & placebo & morphine & clonidine \\
\hline Age $(\mathrm{yr})$ & $81 \pm 1$ & $78 \pm 3$ & $79 \pm 6$ \\
Weight $(\mathrm{kg})$ & $68 \pm 11$ & $70 \pm 9$ & $73 \pm 14$ \\
Height $(\mathrm{cm})$ & $160 \pm 10$ & $163 \pm 9$ & $165 \pm 7$ \\
Women/men ratio & $8 / 4$ & $10 / 2$ & $6 / 6$ \\
ASA class II/III & $3 / 9$ & $8 / 4$ & $3 / 9$ \\
\hline
\end{tabular}

ASA = American Society of Anesthesiologists.

TABLE II Anaesthetic variables during the first $\mathbf{3 0}$ min after Initial Intrathecal Injection

(mean $\pm \mathrm{SD}$ or median (range), $\mathrm{n}=12$ in each group)

\begin{tabular}{llll}
\hline & placebo & morphine & clonidine \\
\hline $\begin{array}{l}\text { Maximal sensory level } \\
\begin{array}{l}\text { Onset time of maximal } \\
\text { sensory level (min) }\end{array}\end{array}$ & $\mathrm{T}_{9}\left(\mathrm{~T}_{4}-\mathrm{L}_{2}\right)$ & $\mathrm{T}_{9}\left(\mathrm{~T}_{4}-\mathrm{L}_{2}\right)$ & $\mathrm{T}_{10}\left(\mathrm{~T}_{4} \cdot \mathrm{L}_{2}\right)$ \\
$\begin{array}{l}\text { Maximal degree of motor } \\
\text { block (Bromage scale) }\end{array}$ & $4(1-4)$ & $42 \pm 6$ & $24 \pm 8$ \\
$\begin{array}{l}\text { Onset time of maxinal } \\
\text { degree of motor }\end{array}$ & $21 \pm 8)$ & $4(0-4)$ \\
block (min) & $21 \pm 8$ & $16 \pm 7$ & $17 \pm 9$ \\
\hline
\end{tabular}

TABLE III Haemodynamic changes during the first 30 min after Initial Intrathecal Injection

(mean $\pm S D, n=12$ in each group)

\begin{tabular}{llll}
\hline $\begin{array}{l}\text { Maximum changes from } \\
\text { baseline values in systolic }\end{array}$ & placebo & morphine & clonidine \\
$\begin{array}{l}\text { arterial pressure } \\
\begin{array}{l}\text { Time to reach maximal } \\
\text { changes in systolic arterial }\end{array}\end{array}$ & $-13 \pm 9^{*}$ & $-25 \pm 13$ & $-24 \pm 11$ \\
$\begin{array}{l}\text { pressure (min) } \\
\begin{array}{l}\text { Maximum changes from } \\
\text { baseline values in heart rate }\end{array}\end{array}$ & $-11 \pm 6$ & $-11 \pm 6$ & $-12 \pm 10$ \\
$\begin{array}{l}\text { Number of paticnts receiving } \\
\text { ephedrine }\end{array}$ & 1 & 3 & 3 \\
\begin{tabular}{l} 
Mean dose of ephedrine $(\mathrm{mg})$ \\
\hline
\end{tabular} & $13 \pm 14$ & $10 \pm 9$ \\
\hline
\end{tabular}

* $P<0.05$ between placebo and the others groups 
TABLE IV Analgesic requirements and secondary effects during the first $24 \mathrm{hr}$ after surgery (median (ranges), $\mathrm{n}=12$ in each group)

\begin{tabular}{llll}
\hline & placebo & morphine & clonidine \\
\hline Time between end of surgery and first analgesic administration $(\mathrm{min})$ & $130(60-240)$ & $330(60-1020)^{*}$ & $200(60-300)$ \\
Total number of analgesic interventions per patient & $4(2-7)$ & $2(1-6)^{*}$ & $5(2-7)$ \\
Number of patients with nausea & 1 & 2 & 0 \\
Number of patients with pruritus & 0 & 3 & 0 \\
\hline
\end{tabular}

* $P<0.05$ between morphine and the other groups

the morphine group and $\mathrm{L}_{2}$ for one patient in the clonidine group. For these patients the duration of surgical analgesia, as defined, was, $134 \pm 22 \mathrm{~min}$ and $163 \pm 48$ min for the placebo and morphine groups respectively ( $P$.NS), and $150 \mathrm{~min}$ for the patient in the clonidine group. The duration of anaesthesia, as defined, was comparable among the three groups: $218 \pm 47 \mathrm{~min}$ for the placebo group, $231 \pm 37 \mathrm{~min}$ for the morphine group and $231 \pm 48 \mathrm{~min}$ for the clonidine group.

The systolic blood pressure decreased in the clonidine and morphine groups compared with the placebo group $(P<0.05)$. In contrast, the variations in heart rate and the need for vasopressors were comparable among the three groups (Table III). No patient required atropine.

After the first $30 \mathrm{~min}$, analysis of haemodynamic variables demonstrated a higher requirement for ephedrine in the clonidine group than in the placebo or morphine groups. In the clonidine group, nine patients required ephedrine $(P<0.05)$ vs 0 and two patients in the placebo and morphine groups. This was confirmed by the larger dose of ephedrine administered to the clonidine group $(21 \pm 14 \mathrm{mg})$ compared with placebo $(0 \mathrm{mg})$ and morphine $(7.5 \pm 3.5 \mathrm{mg})$ groups $(P<0.05)$. No sedative or analgesic drugs were administered during surgery.

When comparing the sedation score during the intraoperative period, three patients in the clonidine group had a maximum score of three whereas all patients in the placebo and morphine groups had a maximum score of two. A respiratory rate $<10 \mathrm{bpm}$ was encountered in four patients of the morphine group, without signs of oxygen desaturation and not requiring treatment.

The time between the end of the surgery and first administration of analgesics was longer $(P<0.05)$ in the morphine group than in the two other groups. Also the number of analgesic interventions during the first 24 hr was lower $(P<0.05)$ in the morphine group than in the placebo or clonidine groups (Table IV). The maximum sedation score in the recovery room was three only for one patient in the clonidine group and no patient developed a respiratory rate $<10 \mathrm{bpm}$.

\section{Discussion}

The results of the present study indicate that, for patients undergoing knee replacement, $0.15 \mathrm{mg}$ clonidine added to $10 \mathrm{mg}$ bupivacaine prolongs surgical analgesia, whereas the addition of $0.15 \mathrm{mg}$ morphine to $10 \mathrm{mg}$ bupivacaine improves the quality of postoperative analgesia. When compared with the morphine group, the shorter duration of postoperative pain relief in the clonidine group can be partly explained by the fewer patients requiring supplemental doses of bupivacaine to complete surgery.

Identical, but not equipotent, doses of clonidine and morphine were compared on clinical grounds, mainly because $0.15 \mathrm{mg}$ clonidine is the dose commonly used with local anaesthetics during spinal anaesthesia, ${ }^{1,2,12-14}$ and because doses of $\geq 0.2 \mathrm{mg}$ morphine have been reported as effective for reducing postoperative pain without producing side effects. ${ }^{6,8}$ Recently, the postoperative analgesic effect of the addition of 0.075 or $0.1 \mathrm{mg}$ clonidine, of $1 \mathrm{mg}$ morphine and of placebo to $13.75 \mathrm{mg}$ bupivacaine were compared during single injection spinal anaesthesia for total hip replacement. ${ }^{4}$ Clonidine alone prolonged the time to regression of sensory block, but morphine consumption during the postoperative period in the clonidine groups was not different from the placebo group and was higher when compared with the morphine group. These findings are consistent with our postoperative data.

Although it is accepted that clonidine prolongs the duration of sensory and motor blocks of bupivacaine spinal anaesthesia, ${ }^{1-4,12,13}$ the mechanism is unknown. ${ }^{15}$ It should be noted that these findings are mostly reported after single injection spinal anaesthesia ${ }^{1-4,13}$ where higher doses of bupivacaine are administered as well as during the postoperative period where the surgical stimulation is absent and where the intensity of the painful stimulus is likely to be lower. In the present study, using continuous spinal anaesthesia, clonidine did not influence the progression and maximal sensory level or degree of motor bloc, but it appears that when $0.15 \mathrm{mg}$ clonidine was added to $10 \mathrm{mg}$ plain bupivacaine, surgical analgesia during total knee 
replacement was prolonged. Thus, only $1 / 9$ patients in the clonidine group $(P<0.05)$ compared with $8 / 10$ in the placebo group and $8 / 11$ in the morphine group required supplementary bupivacaine during surgery because of the appearance of pain at the operative site. These injections were given about $2 \frac{1 / 2}{h r}$ after the initial intrathecal administration of the anaesthetic mixture, the duration of anaesthesia being about four hours. A similar finding concerning the association of $5 \mathrm{mg}$ plain bupivacaine with $0.15 \mathrm{mg}$ clonidine compared with $5 \mathrm{mg}$ plain bupivacaine with placebo was reported during continuous spinal anaesthesia for fractured hip surgery.12 The addition of clonidine, in this survey, delayed the supplementary bupivacaine injection from 84 to 198 min. However, it is not clear whether the supplementary bupivacaine was injected for surgical or for postoperative pain and the duration of anaesthesia or surgery is not reported.

In contrast to the clonidine group, the anaesthetic variables in our study did not differ at any time between the morphine and the placebo groups. These findings indicate that $0.15 \mathrm{mg}$ morphine does not modify the quality of surgical analgesia obtained with $10 \mathrm{mg}$ bupivacaine. However, it has been reported that $0.2 \mathrm{mg}$ morphine added to hyperbaric bupivacaine decreased visceral pain during Caesarean section. ${ }^{16}$

During the first $30 \mathrm{~min}$ after the initial intrathecal injection, a decrease in systolic arterial pressure was observed in patients receiving clonidine and morphine compared with placebo. Afterwards, there was no difference between the placebo and morphine groups whereas the patients in the clonidine group displayed significantly greater haemodynamic instability, characterized by a higher requirement for vasopressors. Although clonidine is known to produce hypotension by inducing sympathectomy, its association with the usual single spinal injection dose of plain bupivacaine (15 $\mathrm{mg}$ ) is not reported to produce a larger decrease in blood pressure than bupivacaine alone. ${ }^{1,2}$ This can be explained because single spinal doses of local anaesthetic produces a higher degree of sympathetic blockade which is not further influenced by the addition of clonidine. In contrast, as also observed in our study, low doses of plain bupivacaine $(5 \mathrm{mg})$ with clonidine $(0.15 \mathrm{mg})$ induce greater decreases in mean arterial pressure than bupivacaine alone. ${ }^{12}$

Whereas the intraoperative decrease in systolic pressure observed in patients receiving clonidine is understandable, there is no explanation for the decrease in systolic pressure observed with morphine during the first $30 \mathrm{~min}$ after the initial intrathecal injection. Hypotension is not described as a side effect of intrathecal morphine administration. ${ }^{17}$ In studies comparing bupivacaine-morphine and bupivacaine-placebo mixtures, the variations in mean arterial pressures were not different ${ }^{5}$ or were not reported. ${ }^{6}$

A respiratory rate of $<10 \mathrm{bpm}$ was observed in four patients receiving morphine during the intraoperative period. This was of short duration since in the recovery room no patient had a respiratory rate $<10 \mathrm{bpm}$. Although three patients in the clonidine group presented a sedation score of three during surgery, the difference in sedation scores between groups was not statistically significant. This absence of difference could be attributed to the preoperative administration of meperidine and promethazine currently used in our institution in elderly patients undergoing major surgery under regional anaesthesia. ${ }^{9-11}$ In our experience, this combination of drugs provides good sedation, reducing the need for intraoperative administration of sedative drugs and allows reliable testing of anaesthesia level during surgery.

In conclusion, whereas the addition of $0.15 \mathrm{mg}$ clonidine to $10 \mathrm{mg}$ bupivacaine during continuous spinal anaesthesia produced a local anaesthetic sparing effect during surgery, the addition of $0.15 \mathrm{mg}$ morphine did not influence the quality of surgical analgesia. The combination of bupivacaine-clonidine-morphine could be useful in obtaining long lasting spinal anaesthesia as well as postoperative pain relief.

\section{References}

1 Racle JP, Benkbadra A, Poy JX, Gleizal B. Prolongation of isobaric bupivacaine spinal anesthesia with epinephrine and clonidine for hip surgery in the elderly. Anesth Analg 1987; 66: 442-6.

2 Bonnet $F$, Diallo $A$, Saada $M$, Belon $M$, Guilbaud $M$, Boico $O$. Prevention of tourniquet pain by spinal isobaric bupivacaine with clonidine. Br J Anaesth 1989; 63: 93-6.

3 Niemi L. Effects of intrathecal clonidine on duration of bupivacaine spinal anaesthesia, haemodynamics, and postoperative analgesia in patients undergoing knee arthroscopy. Acta Anaesthesiol Scand 1994; 38: 724-8.

4 Fogarty DJ, Carabine UA, Milligan KR. Comparison of the analgesic effects of intrathecal clonidine and intrathecal morphine after spinal anaesthesia in patients undergoing total hip replacement. Br J Anaesth 1993; 71: $661-4$.

5 Jacobson L, Chabal C, Brody MC. A dose-response study of intrathecal morphine: efficacy, duration, optimal dose, and side effects. Anesth Analg 1988; 67: 1082-8.

6 Kirson LE, Goldman JM, Slover RB. Low-dose intrathecal morphine for postoperative pain control in patients undergoing transurethral resection of the prostate. Anesthesiology 1989; 71: 192-5. 
7 Grace D, Bunting $H$, Milligan KR, Fee JPH.

Postoperative analgesia after co-administration of clonidine and morphine by the intrathecal route in patients undergoing hip replacement. Anesth Analg 1995; 80: 86-91.

8 Milner $A R$,Bogod $D G$, Harwood RJ. Intrathecal administration of morphine for elective Caesarean section. Anaesthesia 1996; 51: 871-3.

9 Van Gessel EF, Forster A, Gamulin Z. Surgical repair of hip fractures using continuous spinal anesthesia: comparison of hypobaric solutions of tetracaine and bupivacaine. Anesth Analg 1989; 68: 276-81.

10 Van Gessel EF, Miege B, Forster $A$, Salvaj $G$, Fathi $M$, Gamulin Z. Comparison of hyperbaric solutions of bupivacaine and tetracaine during continuous spinal anaesthesia. Can J Anaesth 1992; 39: 323-9.

11 Gaggero $G$, Van Gessel E, Forster A, Gosteli P, Gamulin $Z$. Comparison of $5 \mathrm{mg}$ tetracaine diluted in $1 \mathrm{ml}, 2 \mathrm{ml}$ and $4 \mathrm{ml}$ of $10 \%$ glucose for spinal anesthesia. Acta Anaesthesiol Scand 1993; 37: 697-701.

12 Klimscha W, Chiari A, Krafft $P$, et al. Hemodynamic and analgesic effects of clonidine added repetitively to continuous epidural and spinal blocks. Anesth Analg $1995 ; 80$ : 322-7

13 Racle JP, Poy JY, Benkbadra A, Jourdren L, Fockenier $F$. Prolonging hyperbaric bupivacaine spinal anaesthesia with adrenaline and clonidine in the elderly. (French) Ann Fr Anesth Reanim 1988; 7: 139-44.

14 Boico $O$, Bonnet $F$, Mazoit $J X$. Effects of epinephrine and clonidine on plasma concentrations of spinal bupivacaine. Acta Anaesthesiol Scand 1992; 36: 684-8.

15 Eisenach JC, De Kock $M$, Klimscha $W .{ }_{2}$-Adrenergic agonists for regional anesthesia. A clinical review of clonidine (1984-1995). Anesthesiology 1996; 85: 655-74.

16 Abouleishe E, Rawal N, Fallon K, Hernandez D. Combined intrathecal morphine and bupivacaine for cesarean section. Anesth Analg 1988; 67: 370-4.

17 Chaney $M A$. Side effects of intrathecal and epidural opioids. Can J Anaesth 1995; 42: 891-903. 